\title{
Coping with institutional complexity: Responses of management scholars to competing logics in the field of management studies
}

\author{
Bernadette Bullinger ${ }^{a}$, Alfred Kieser ${ }^{\mathrm{b}, 1, *}$, \\ Simone Schiller-Merkens ${ }^{c, 2}$
}

a University of Innsbruck, Universitätsstraße 15, Innsbruck A-6020, Austria

${ }^{\mathrm{b}}$ Zeppelin University, Am Seemooser Horn 20, Friedrichshafen D-88045, Germany

${ }^{c}$ Max Planck Institute for the Study of Societies, Paulstr. 3, Cologne D-50676, Germany

\author{
KEYWORDS \\ Applied research; \\ Basic research; \\ Institutional logics; \\ Institutional complexity; \\ Management studies; \\ Relevance; \\ Rigor; \\ Rigor-relevance gap
}

\begin{abstract}
In contrast to existing studies on the issue of the rigor-relevance gap, we do not discuss in this article how to bridge it but analyze the responses of management scholars to it. Referring to institutional theory, we argue that the gap is related to different logics of research aimed at scientific progress (basic research) or at relevant knowledge (applied research). Analyzing publications in leading scholarly and practitioner-oriented management journals between 1961 and 2010, we identify a variety of responses. Management scholars address the demand for relevance by providing implications-for-practice sections and the development of approaches for the production of relevant knowledge. Most of them believe that the dominant logic of basic research integrates the demand for both rigor and relevance. However, we find evidence for the existence of competing logics: researchers do not base applied research on their basic research, and they tend to publish applied research in later periods of their careers. We conclude that compartmentalization is the dominant response strategy of management researchers.
\end{abstract}

(C) 2015 Elsevier Ltd. All rights reserved.

\footnotetext{
Authors appear in alphabetical order and contributed equally to the paper.

* Corresponding author. Tel.: +49 754160091122.

E-mail addresses: bernadette.bullinger@uibk.ac.at

(B. Bullinger), alfred.kieser@zu.de (A. Kieser), ssm@mpifg.de

(S. Schiller-Merkens).

1 Tel.: +4975416009 1122 .

2 Tel.: +492212767256.
}

\section{Introduction}

The issue of a gap between rigor and relevance in academic management research (Hodgkinson, Herriot, \& Anderson, 2001; Kieser, Nicolai, \& Seidl, 2015; Rynes, Bartunek, \& Daft, 2001) started to develop in 1958 with the publication of two reports on the quality of business education in the United 
States, one by the Ford Foundation (Gordon \& Howell, 1959), the other one by the Carnegie Foundation (Pierson, 1959). Both reports came to the conclusion that American business schools resembled trade schools lacking a strong scientific foundation. Their main recommendation was to base education on rigorous scientific research. For Pierson (1959) (p. 313), the central prerequisite was to create generalizable knowledge that could be applied only after it was tested scientifically. Gordon and Howell (1959) (p. 382) more explicitly asked for

more applied research at a higher analytical level ... [which] implies the formulation of challenging hypotheses, the development and use of more sophisticated analytical tools, including more utilization of concepts and findings from the various social sciences and greater reliance on the tools of mathematics and statistics, and the systematic collection of detailed and reliable data.

Both reports shared an understanding of the sciences: theories that explain phenomena can also be used for planning interventions in the pursuit of practitioners' goals. Thus the intention of both reports was to improve the quality of research for business practitioners just as research in the natural sciences produces findings that increase the practical value of engineering. Business schools accurately followed the reports' advice: they hired researchers from neighboring disciplines like psychology, sociology, or economics who were experienced in formulating challenging hypotheses, developing sophisticated analytical tools, using statistics and mathematics, and collecting detailed and reliable data. The newly recruited scholars infused the emerging field of management studies with a research logic that resembled the “hypothetico-deductive” approach (de Rond \& Miller, 2005, p. 323) of the natural sciences (Khurana, 2007; Schlossman, Sedlak, \& Wechsler, 1987). Even as they started to address management problems, these scholars continued to follow the principles of rigorous science in their research practices: objectivity and abstractness, reliance on methodological criteria for truth and standardized methods of scientific inquiry, disinterestedness, organized skepticism, and the conviction that scientific results can only be evaluated and further developed by scientists (Merton, 1973). Furthermore, they founded academic journals in which they could publish their rigorously gained research results, and they developed $\mathrm{PhD}$ programs in which young researchers were to be taught how to pursue rigorous research (Fourcade \& Khurana, 2013).

Thus, research in business schools has steadily increased in sophistication. However, in contrast to the expectations of the authors of the Ford and Carnegie Foundation reports, rigor in research has not increased practical relevance. On the contrary, observers notice a steadily growing gap between the rigorousness of research and its relevance for practice. For example, Bennis and O'Toole (2005, p. 98) argue that research in business schools has shifted towards "a model of science that uses abstract financial and economic analysis, statistical multiple regressions, and laboratory psychology," and that this model of basic research is of little relevance to practitioners. They are convinced that the shift towards exactly the kind of research recommended in the reports caused the gap. They and others (Beer, 2001; Ivancevich, Duening, \& Lidwell, 2005; Pfeffer \& Fong, 2002; Schibrowsky, Peltier, \& Boyt, 2002; Trank \& Rynes, 2003) claim that business shares more characteristics with professions like medicine and law than it does with natural sciences, and that research in the field of management studies should therefore adopt the alternative model of applied research.

How do management scholars respond to the issue of the rigor-relevance gap? Existing studies on the topic are mainly concerned with the question of how to bridge the gap. We do not yet know much about the coping strategies of individual scholars. Because they are confronted with the rising demand for practical relevance and with two alternative research models, each shaped by a particular institutional logic, do management scholars perceive the gap as a problem, and if so, how they respond to it? To address these questions, we draw on the institutional logics perspective in institutional theory, in particular on work relating to the strategies actors use to cope with situations of institutional complexity. Empirically, we analyze the publication practices of scholars in a sample of leading academic and practitioner-oriented management journals, using a timeframe between 1961 and 2010. We thereby assume that an analysis of publications offers insights into both the logics guiding research in the field and the scholars' strategies for coping with the institutionally complex situation of two competing research logics.

In the first section of our paper, we elaborate on the rigorrelevance debate and introduce the idea that basic research and applied research in the field of management studies follow competing institutional logics. In the second section, we introduce the coping strategies that actors can apply in such institutionally complex situations. In the subsequent sections we then describe our methodological approach and present and interpret our findings by making use of the institutional framework. Summarizing our findings in the discussion section, we further reflect on whether the gap is genuinely a problem for practitioners or whether it is a construction of management scholars. We conclude with implications for the future development of the field of management studies.

\section{Rigor and relevance and competing institutional logics in management studies}

When we use an institutional logics perspective (Thornton, Ocasio, \& Lounsbury, 2012), basic research and applied research in the field of management studies can be conceptualized as two competing institutional logics, each related to its own set of organizing principles. To start with, the main organizing principle of the logic of basic research is scientific rigor. It requires that problems be formulated on the basis of one or several theories and are dealt with by using methods that are acknowledged as scientific (Kieser \& Leiner, 2009). It aims to replace (scientifically) false statements with true ones. Scholars criticize generally accepted assumptions about the explanation of phenomena or their colleagues' research results for being based on wrong or incomplete theories, for using the wrong methods, or for using appropriate methods inadequately. With such criticism in mind, they carry out research based on modified theories and methods, in the hope that the scientific community will be convinced of the validity of their results, which will then replace the incorrect findings. They submit their findings to publishers of scientific journals or monographs, who, in turn, 
ask researchers familiar with the subject to review them. Positive outcomes of this review process result in scientific publications, which are the basic elements of communication in science.

Under the logic of applied research, in contrast, scholars are expected to produce knowledge that proves useful for solving practical problems. The central organizing principle of this logic is practical relevance, that is, to focus research on the solution of practical problems and not on the explanation of problems resulting from the scholarly discourse. It is not important that phenomena are explained by appropriate theories and methods, or that the new knowledge replaces false scientific knowledge. It is sufficient to provide knowledge with which specific practical problems can be tackled more effectively than with previous knowledge. A substantial part of research in medical schools, for example, aims at advancing the effectiveness of practices in the prevention, diagnosis, and treatment of diseases through clinical trials (Ludmerer, 2010; Rosenberg, 1987; Rothstein, 1987). It follows a logic that is different from the logic of basic research insofar as the central aim is to improve practices, not advance the development of medical theory. Under this logic, technology is considered more important than theory, and results are published in practitioner-oriented journals.

Proponents of a shift towards the logic of applied research in management studies argue that this logic combines principles of rigorous research with those of practitioner-oriented problem-solving (Hodgkinson et al., 2001; Hodgkinson \& Rousseau, 2009). Others, however, consider this logic as incompatible with the dominant logic of basic research because these two logics have conflicting organizing principles and prescribe essentially different actions, goals, and means (Kieser \& Leiner, 2009; Nicolai, 2004). In light of these conflicting views, our study asks how management scholars deal with the demand for an alternative logic in the field. We therefore analyze the extent to which the logic of applied research shapes scholarly practices and examine how management scholars handle two logics with supposedly incompatible demands.

\section{Responses to competing institutional demands}

"Institutional logics are the organizing principles that shape the behavior of field participants" (Reay \& Hinings, 2009, p. 631). Initial studies in the institutional logics perspective investigated cases in which one organizing principle or dominant logic was replaced by another (Thornton, 2001, 2002). Current studies focus on the implications of institutional complexity. In institutionally complex situations, multiple logics coexist in a field, even when these are associated with competing practices and rules (e.g., Lounsbury, 2007; Marquis \& Lounsbury, 2007; Meyer \& Höllerer, 2010; Reay \& Hinings, 2005; Reay \& Hinings, 2009; Scott, Ruef, Mendel, \& Caronna, 2000). Different logics can be perceived as incompatible when they prescribe different actions, goals, or means (Greenwood, Raynard, Kodeih, Micelotta, \& Lounsbury, 2011; Pache \& Santos, 2010). Consequently, in situations of competing institutional demands, it becomes an open question how organizations and individuals cope with this incompatibility.

The growing research on responses to multiple institutional demands concentrates on how organizations can respond to incompatible institutional demands. For instance, Kraatz and Block (2008) describe four strategies that organizations might employ to maintain their legitimacy when facing plural institutional demands. First, they could try to resist conflicting demands by only complying with some claims while denying the importance of others. "Compartmentalizing" is identified by Kraatz and Block (2008) as a second strategy which enables organizations to conform to different institutional demands by separating these into various organizational units or time sequences. Third, organizations might find some balance between competing demands not by separating them but by reaching a "reluctant mutual acceptance” (Kraatz \& Block, 2008, p. 251). This strategy might be especially important when there is a mutual dependence between the different claims. As an example of mutually dependent groups, the authors refer to a business school faculty with members who focus on teaching and members who are driven by research; the demands of both need to be balanced on the organizational level. Fourth, organizations might aim to become "institutions in their own right” (Kraatz \& Block, 2008, p. 251), claiming authority to define relevant legitimacy criteria against which they are measured. Their fact-like character, which depends on a specific organizational identity, then shields them to a certain degree against external demands.

Pache and Santos (2010) and Greenwood et al. (2011) also point to compartmentalizing as a strategic response to plural institutional logics. This coping strategy entails "partitioning/compartmentalizing an organization into different mindsets, normative orders, practices and processes" (Greenwood et al., 2011, p. 354) by defining separate subunits that deal with particular logics or sets of demands. Researchers (e.g., Bromley \& Powell, 2012, p. 23) argue that the notion of compartmentalization broadly refers to the concept of decoupling as an organization's attempt to separate symbolic compliance from actual practices (Meyer \& Rowan, 1977). It also includes another form of decoupling, as developed by Bromley and Powell (2012), in which the means (i.e., policies) that are actually implemented in organizations are decoupled from the ends. Means-end decoupling occurs "when policies are implemented but the link between formal policies and the intended outcome is opaque" (Bromley \& Powell, 2012, p. 489). It differs from the classical notion of decoupling as policy-practice decoupling, whereby action is buffered from policy through symbolic adoption, enabling exposed rules to remain unimplemented (see also Pache \& Santos, 2010). Finally, according to Brunsson (1993) (p. 501), producing hypocrisy is an alternative way for making ideas and actions appear consistent: "Through hypocrisy, the ideas of the constituency are isolated from action."

We argue that the responses of organizations to competing institutional logics are a useful analytical starting point to also investigate the responses of individuals. We thereby follow Thornton and Ocasio (2008) call for studies that shed light on responses of individuals to institutional complexity and on how these responses help us understand the coexistence of incompatible logics in a field. Thus, analogous to the differentiation of organizational responses to institutional complexity, we are interested in understanding the kinds of strategies that individual actors, in our case management scholars, use when reacting to competing institutional logics in the field of management studies. 


\section{Methodology}

We assume that journal publications provide good insights into the research practices of the field of management studies and into the logics guiding these practices: journal publications reflect the kinds of research subjects and analytical approaches that are acknowledged and legitimated by other members in the field, namely the editors and reviewers. These field members influence what is published and thus perceived as fulfilling the research standards of management studies. Hence, analyzing publication practices helps us understand how management scholars perceive the increasing institutional demand for practical relevance, whether the logic of applied research has gained momentum in the field of management studies, and, if so, how management scholars handle the institutional complexity of two competing logics in their publication practices.

\section{Selection of management journals}

Following other researchers who analyzed issues as reflected in academic publications (Busenitz et al., 2003; Lockett, Moon, \& Visser, 2006), we selected the scholarly management journals on the basis of their influence, as measured by their impact factors. Our sample includes the scholarly journals Academy of Management Journal (AMJ), Academy of Management Review (AMR), Administrative Science Quarterly (ASQ), Organization Science (OS). In 2010, the impact factors of these journals all ranked at the top of the category "management" on the ISI Web of Knowledge/Social Science Citation Index. Furthermore, the inclusion of AMJ and AMR grants insight into the responses which a dominant actor, the Academy of Management (AOM), the leading scholarly association in the field, regards as appropriate to handle the existence of competing research logics. We further included the Journal of Management Studies (JMS) and the British Journal of Management (BJM) in order to capture the European contribution to the debate, thereby allowing a more complete picture of international developments.

We further added practitioner-oriented journals to our sample, including the Harvard Business Review (HBR), California Management Review (CMR), Academy of Management Executive (AME), ${ }^{1}$ MIT Sloan Management Review (MIT SMR), formerly Sloan Management Review (SMR), Industrial Management Review (IMR), and Business Horizons (BH). We selected these journals because, in their mission statements, they explicitly refer to a bridging function between management theory and practice. ${ }^{2}$ Our analysis starts with the 1961 volumes, when we expected to find reactions to the foundations' reports that led to the formation of

\footnotetext{
${ }^{1}$ While the Academy of Management Executive aimed at practicing managers, the renamed Academy of Management Perspectives seeks to address academic readers and was therefore excluded from our empirical analysis.

2 We refer to the aims of the journals as stated on their web pages on May 24, 2009: http://harvardbusiness.org/about-us, http://cmr. berkeley.edu/submission_guidelines.html, http://www.aomonline. org/aom.asp?id=95, and http://sloanreview.mit.edu/about/, http:// www.elsevier.com/wps/find/journaldescription.cws_home/620214/ description\#description.
}

the management studies field, and ends with volumes published in 2010. We used two different journal databases, Business Source Premier and the ISI Web of Knowledge/ Social Science Citation Index.

\section{Data and analysis}

To select articles on the rigor-versus-relevance debate within the data set just described, we searched the Business Source Premier database for scholarly articles, using specific but deliberately broad keywords (rigor/rigour, relevance, management science, management studies, administrative science, management education, business school, academic AND practitioner, scholar AND practitioner, scholar AND manager, academic AND manager, management research, applied science). To identify relevant articles, we read the abstracts of all 937 articles resulting from our Business Source Premier search. Two of us undertook separately the task of determining which of the articles dealt with the debate and which did not. Then we compared our findings and discovered that we agreed in more than 95 percent of the cases. We resolved our differences of categorization for 49 articles by way of discussion. In the end, we identified 127 articles that dealt with the rigor-versus-relevance debate. We used these articles for a frequency analysis to assess the emergence of the logic of applied research in the field over time (see Increasing acknowledgement of applied research). Furthermore, to learn how management scholars cope with institutional complexity, we additionally conducted the following analyses: in a qualitative content analysis of the 127 articles, we tried to find out whether the logic of basic research is seen as causing a lack of relevance in management research and whether institutional changes towards the logic of applied research are envisaged, in particular through conceptualizing and applying new research methods. We were thereby interested in understanding whether management scholars regard the logic of basic research and the logic of applied research as conflicting logics, or whether they perceive them, in principle, as compatible ones (see Scholars' perception of institutional demands). Additionally, we were interested in whether management scholars themselves apply the new research methods that they discuss (see Use of methodological practices from the logic of applied research).

In the next step, we explored the extent to which management researchers, in their publications, explicitly deal with practical implications of their research results. In this analysis we considered the same scholarly journals (AMJ, AMR, ASQ, OS, BJM, and JMS), while taking into consideration, however, the limited data set of articles addressing the rigor-relevance gap as we had in our first step, as well as the articles published in the chosen fifty-year period. We registered the frequency of particular keyword combinations in the selected scholarly journals, including "practical/managerial implications," "implications for practice," "implications for practitioners," "implications for managers," and other combinations of these words to gain further information on how management scholars react to the demand for more practical relevance in the management studies field (see Practical implications sections in scholarly articles).

In addition, we analyzed the content of 67 articles in practitioner-oriented journals in order to understand whether management scholars distinguish between practices 
that are shaped by the logic of basic research and those that are guided by the logic of applied research (see Publications in practitioner-oriented journals). For this analysis, we sampled only the practitioner-oriented articles of the ten most-cited management scholars (Podsakoff, MacKenzie, Podsakoff, \& Bachrach, 2008) and identified the extent to which these articles are based on the authors' research publications in scholarly journals. Our assumption in choosing this sample was that the most-cited management scholars can be supposed to be the ones who base their practitioneroriented articles as much as possible on their research.

Finally, we analyzed whether publication practices are guided by different logics when taking into account the lifetime career of management scholars (see Publication practices throughout a scholarly career). To examine whether such a difference between early and late career phases exists, we conducted chi-square tests using a sample of publications by members and former members of leading U.S. business schools, as listed by the Financial Times (FT) Business School Ranking $^{3}$ (namely, Wharton School, Harvard Business School, Columbia Business School, Stanford University Business School, and MIT Sloan School of Management), who published at least one article in both journal genres between 1961 and 2010. We thereby assumed that these scholars provide role models for other researchers in the field. ${ }^{4}$

\section{Findings}

\section{Increasing acknowledgement of applied research}

In this section we present results on management researchers' responses to the critique that they have emphasized basic research and the principle of rigor at the cost of applied research focusing on relevance. We show that they are aware of the rigor-relevance gap and express their concern by increasingly writing on this subject.

Fig. 1 shows the publication rates of articles on rigor versus relevance in five-year intervals over the period from 1961 to 2010. As illustrated, the frequency of publications of this type has increased over time. Until about 1996, there were minor waves of articles on this topic, but a significant increase is observable from this year onward. This is predominantly due to the increase in the number of articles on the gap published in the two scholarly journals of the Academy of Management, AMJ and AMR, and in BJM. This finding shows that prominent researchers and editors, predominantly in the most established journals in the field of management studies, acknowledge the emergence of another, and possibly conflicting, organizing principle in their field: practical relevance. Given that the logic of applied research forms part of the debate on rigor and relevance, this debate also reflects the emergence of the logic of applied research in the field, if only on a discursive or rhetorical level.

\footnotetext{
${ }^{3}$ We draw on the Financial Times Global MBA Rankings 2011, as published on the Financial Times webpage on April 29, 2011, http:// rankings.ft.com/businessschoolrankings/global-mba-rankings-2011 (first published on January 31, 2011).

${ }^{4}$ More information on the sample for this research question is provided in the findings section.
}

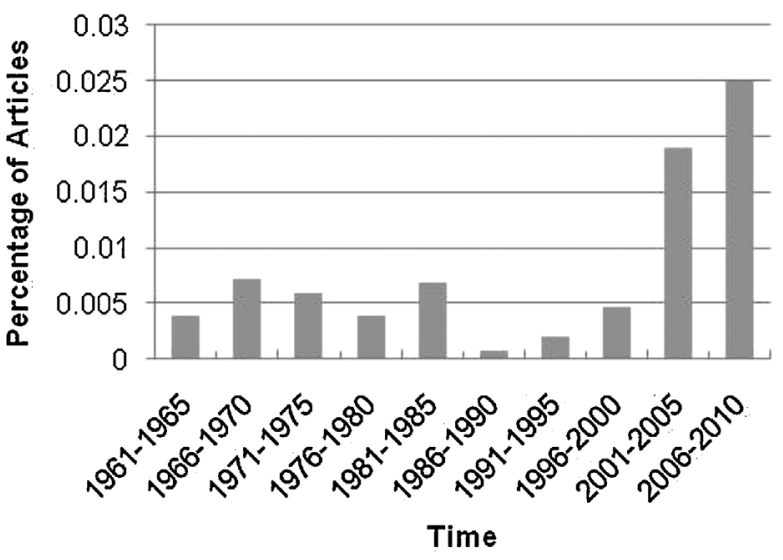

Fig. 1 Percentage of articles on the rigor-relevance gap in total (AMJ, AMR, ASQ, OS, BJM, JMS).

\section{Scholars' perception of institutional demands}

A crucial question in the rigor-versus-relevance debate is whether the dominant logic of basic research is capable of providing a basis for applied research as well. We investigated this question by drawing on the 127 articles in our sample that explicitly deal with the rigor-relevance gap. Twelve of these articles are editorials. The majority of these articles express the opinion that basic research also serves the needs of practice (see, e.g., Barney, 2005; Bell, 2009; Bettis, 1991; Mintzberg, 1977; Saari, 2007; Salipante \& Aram, 2003). Thus for them, the rigor-relevance gap is essentially a communication problem. Scholars have to communicate intensively with practitioners to learn about their problems. Then they have to research these problems and communicate their results in a way that practitioners can understand. Since problems in management practice usually do not fall neatly into the category of one particular discipline, interdisciplinary research has to be conducted. Also, it is recommended to intensify activities that translate research results into practice, for example by including even more - or more extensively - informative sections on practical implications in their academic publications, by publishing results in professional journals and using a language that practitioners can understand, and by demonstrating the usefulness of their research when teaching students and training executives.

Many authors argue that research that aspires to have a practical use requires a different epistemology than the usual research in management studies. Consequently, they develop new methods but usually do not discuss the compatibility of these methods with the dominant logic of basic research. In most cases, compatibility is assumed without any explicit reference to this subject. The new epistemologies suggested are as follows: collaborative research (Amabile et al., 2001; Bartunek, 2007; Mohrman, Gibson, \& Mohrman, 2001; Van de Ven \& Johnson, 2006), action research as a special form of collaborative research (Druskat \& Wheeler, 2003; Eden \& Huxham, 1996), science of management design (Starkey, Hatchuel, \& Tempest, 2009; Van Aken, 2004; Van Aken, 2005), Mode 2 research (Burgoyne \& James, 2006; Huff, 2000; Kelemen \& Bansal, 2002; MacLean, Maclntosh, \& Grant, 2002; Mitev \& Venters, 2009; Starkey \& Madan, 2001; 
Tempest \& Starkey, 2004; Tranfield \& Starkey, 1998), and evidence-based management (Rousseau \& McCarthy, 2007). ${ }^{5}$

The majority of authors implies that it is possible to produce research results that are simultaneously rigorous and relevant, while conceding that not all research must be so. For example, Hodgkinson and Rousseau (2009) (p. 534) assert that "contemporary management research demonstrates numerous approaches to doing research of high scholarly quality and practical relevance." However, their way to assess relevance consists of practitioners' interest in certain theories, not of the application of these theories into solutions that solved existing problems. In very few articles, a trade-off between rigor and relevance is conceded, but different implications are drawn. Authors such as Vermeulen (2007) or Tushman and O'Reilly III (2007) point out that "pure" research whose findings are published in highly ranked academic journals, on the one hand, and research that can be communicated to practitioners, on the other, each require a different kind of effort, but the authors assure us that the extra effort invested into working out relevance pays off by improving both kinds of activities.

It takes courage to step onto the thorny road to relevance, and it takes cheerfulness to truly enjoy and sustain the journey and the laborious interaction with the real world of organizations. Yet if you commit to speaking with people in practice about your work and force yourself to formulate and undertake research that also matters to them, at the end of the day, who knows, they might even listen. (Vermeulen, 2007, p. 760)

McGahan (2007) and Kieser and Leiner (2009) argue that basic research is a system hardly accessible to practitioners, but that researchers can inspire practitioners to rethink conventional solutions by confronting them with "counterintuitive insights" (McGahan, 2007, p. 249) or by demonstrating that accepted solutions do not deliver good performance when conditions have changed.

A minority of authors concedes that basic research and the search for practical solutions require different logics, although they do not always provide theoretical underpinnings for that assumption (e.g., Astley \& Zammuto, 1992; Gulati, 2007; Markides, 2007; McGrath, 2007; Mowday, 1997; Nicolai, 2004; Pfeffer, 2007; Shapiro, Kirkman, \& Courtney, 2007; Simon, 1967; Thomas \& Tymon, 1982). For example, Simon (1967, p. 16) argues that any attempt to organize collaboration between practice-oriented and research-oriented faculty members is like "mixing oil with water: it is easy to describe the intended product, less easy to produce it." Astley (1984) (p. 269) argues that "it appears that the increasing emphasis in management studies upon matters of epistemological validity, methodological rigour, and theoretical abstraction is actually widening the gap between theory and practice." In more recent discussions, a few authors perceive an inconsistency between basic and applied research but argue that, in the long run, it can - and must - be avoided. For example, Gulati

\footnotetext{
${ }^{5}$ Whereas collaborative research, action research, design approaches, and Mode 2 seek to include the practitioner's perspective in the research process, evidence-based management holds that a thorough pursuit of the logic of basic research reduces the rigorrelevance gap.
}

(2007) (p. 777) sees management researchers as falling into two camps - "“serious scholars' or 'management types"” and expresses the hope that it will eventually be possible to define a new domain, "one that replaces 'either-or' with 'and"' and thus to provide one big tent for all researchers. He then asks: "If such a tent is not feasible, especially in the short term, can we at least learn to sit simultaneously under multiple umbrellas and occasionally invite strangers into our ovals of shade?" (Gulati, 2007, p. 780).

The underlying rationale of most articles seems to be as follows: if the trade-off between rigor and relevance can be resolved, in principle, it is not necessary to evoke changes in the predominant institutional logic of basic research, for example, by changing the system of reviewing scholarly work or the criteria for promotional decisions. Markides (2007) (p. 763) warns:

Before embarking on radical surgery, such as changing the academic incentive system or subcontracting managerially relevant research to specialists - both of which are, in my opinion, remedies that are worse than the disease - it may be worthwhile to step back and take a fresh look at the problem.

His remedy consists of recommending different research strategies for younger and older researchers (thus implicitly conceding a conflict): "We should encourage young academics to avoid the time-consuming exercise of trying to publish their research in managerial journals and strive instead to bring their research findings into their classroom teaching" (Markides, 2007, p. 766). ${ }^{6}$

A minority of authors explicitly argues in favor of regulative changes in the systems of incentives, promotion, or reviews that are related to the logic of applied research. For example, Pfeffer (2007) (p. 1342) maintains that

since citations measure scientific impact only imperfectly and, moreover, we are presumably concerned about the effects of research on professional practice above and beyond just its scientific impact, we ought to assess contributions along those broader dimensions measuring the effects of our work as well.

Most authors in this group (see, e.g., Cohen, 2007, p. 1017; Thomas \& Tymon, 1982; Vermeulen, 2007, p. 758) do not present detailed recommendations but generally propose that relevant research should be rewarded far more than it has been.

\section{Use of methodological practices from the logic of applied research}

Since quite a few articles discussing the rigor-relevance gap propose new epistemologies in order to achieve more practical relevance, we sought to assess how many articles actually base their empirical research on one of these approaches. We thereby assumed that a widespread application of the new methodological practices in management

\footnotetext{
${ }^{6}$ The articles by Markides (2007) and Gulati (2007) appeared in an Academy of Management Editors' Forum on Research with Relevance to Practice in Honour of Sumantra Ghoshal.
} 


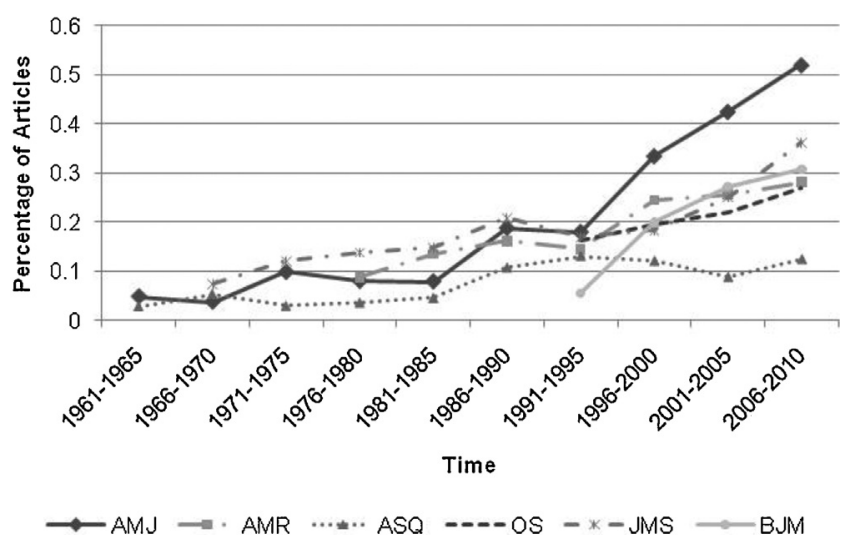

Fig. 2 Percentage of articles mentioning practical implications.

research would indicate acquiescence to institutional demands stemming from the logic of applied research. Of the 127 articles that we categorized as dealing with rigor versus relevance, nineteen articles include empirical analyses, yet only three of these articles present results from empirical applications of the proposed gap-bridging methodologies. ${ }^{7}$ These include results from collaborative research projects involving academics and practitioners (Amabile et al., 2001; Mohrman et al., 2001), and findings from Mode 2 research (Burgoyne \& James, 2006). Thus, only a small fraction of articles actually apply the proposed epistemologies with which the logic of applied research would manifest itself within central research practices, meaning specifically, methodological practices.

\section{Practical implications sections in scholarly articles}

Furthermore, we were looking for insights on whether scholars have started to elaborate on the practical usefulness of their research results as a reaction to the existence of the logic of applied research in the field of management studies. We therefore used a keyword combination in search of all articles in the selected scholarly journals (AMJ, AMR, ASQ, OS, BJM, and JMS) on EBSCO's Business Source Premier database from 1961 onwards. The results comprise articles that mention "practical/managerial implications," "implications for practice," "implications for practitioners," "implications for managers," and other combinations of these words. As Fig. 2 shows, the number of articles that contain at least one of these terms has increased substantially since 1961. The increase was greater in AMJ than in other journals, presumably indicating the editorial policy of this AOM-based journal, which focuses on publishing empirical studies.

\section{Publications in practitioner-oriented journals}

In this section we compare articles in practitioner-oriented journals with articles in scholarly journals. Publications in

\footnotetext{
${ }^{7}$ Since the new methods have been suggested as gap-bridging, it is very unlikely that they have been applied in articles without reference to the gap and that we have thus overlooked them.
}

practitioner-oriented journals are another important practice that has been suggested in response to the rising demand for practical relevance. Analyzing practitioner-oriented articles, we further sought to understand how management scholars respond to the different institutional demands from the logic of basic research and from the logic of applied research. We therefore focused on articles that the ten mostcited management authors published between 1976 and 2010 in the practitioner-oriented journals of our sample.

According to Kelemen and Bansal (2002), in academic articles, authors usually start with a comprehensive review of the literature, develop hypotheses on the basis of a critique of prior theoretical conceptualizations and research findings, and, finally, enrich knowledge by empirically testing their hypotheses. In contrast, articles in practitioneroriented journals tend to present "success stories," best practices, and principles ("what managers should do" and "what managers should avoid"). Miller, Greenwood, and Hinings (1997) (p. 74) perceive a "schism" between "normative" and "academic" publications on organizational change which they attribute to the way

writers treat organizational contexts [assuming a need for change vs. having to explain such a need], acknowledge different interest groups in organizations [identifying with the interests of top management vs. identifying with multiple groups], and attempt to grapple with the critical pessimism of academic research.

Our findings corroborate the differences between academic publications and publications for practitioners (Table Al, Supplementary Data). Between 1976 and 2010, the ten most-cited authors published 67 articles $^{8}$ in the practitioner-oriented journals of our sample. In nineteen of these studies, the authors present empirical findings from their own - basic - research. However, when authors discuss their own empirical studies, they do it in a simple form by showing graphs or frequency distributions. If they discuss methods at all, they do it in just a few lines. One article is based on a model analysis. The remaining 47 articles are essays, that is, they neither present empirical results nor a model analysis. In ten of these articles, the author(s) explicitly referred to one or more corresponding academic articles. In fourteen articles, we could identify corresponding academic articles by comparing topics, co-authors, year of publication and empirical findings presented. However, references to the authors' own empirical studies are usually not very detailed. A typical example is: "Our understanding of patching emerged from almost a decade of research into the reasons behind corporate success in high-velocity, intensely competitive industries" (Eisenhardt \& Brown, 1999, p. 75). In their articles for practitioners, researchers rarely build on their research findings to develop recommendations. In the few cases in which they try to do that, the inferences drawn for practitioners generally do not correspond with the scientific results reported in the academic articles. It seems that the differences in the crafting of publications cannot be explained by referring to a necessity to translate basic

\footnotetext{
${ }^{8}$ We excluded editorials, interviews, case studies, and book reviews.
} 
research into a language practitioners can understand. A discussion of theories and concepts - a common feature of academic articles - could be found in only 28 articles. However, in comparison with academic articles, these conceptual discussions are restricted to a limited number of approaches, mostly two. Not a single article explicitly introduces hypotheses.

In the majority of cases, practitioner-oriented articles only provide background information on an author's research in a loose manner. For example, having published a number of academic articles on high velocity environments (Bourgeois \& Eisenhardt, 1988; Eisenhardt, 1989; Eisenhardt \& Bourgeois, 1988), Eisenhardt and her colleagues turn to general topics in practitioner-oriented journals, such as pacing (Eisenhardt \& Brown, 1998) or patching (Eisenhardt \& Brown, 1999). They thus refer to concepts that she and her co-authors had not previously introduced in that form in academic articles. Another example is Hambrick and his co-authors, who publish research on strategy (Geletkanycz \& Hambrick, 1997) and on top management teams (Hambrick, Davison, Snell, \& Snow, 1998) in academic journals and utilize the accumulated knowledge for practitioner-oriented articles on such general themes as “Are you sure you have a strategy?” (Hambrick \& Fredrickson, 2005) or "Outside directors with a stake: The linchpin in improving governance" (Hambrick \& Jackson, 2000). Forty-nine practitioner-oriented articles contain one or more success stories. From these success stories and their general discussion, the authors delineate how-to principles, often supplemented by checklists, step-models, or simple analytical tools.

To conclude, in practitioner-oriented articles, authors only cursorily refer in one of three ways to their basic research published in academic journals: (1) in most cases, the authors do not relate to their empirical findings but discuss problems of interest for practitioners that are connected with their own and other scholars' research in nonspecified ways, or (2) vaguely refer to their empirical work, or (3) if they refer to specific research, they do not present details on methods, contingencies, or more differentiated statistics that would help the reader to evaluate the strength and significance of findings-and the risks of implementing recommendations. These findings show that the most-cited scholars in the field of management studies are conforming to different logics when crafting their publications for academics or for practitioners. When publishing in academic journals they adapt to the logic of basic research; and when writing for practitioner audiences they conform to the organizing principles of the logic of applied research.

\section{Publication practices throughout a scholarly career}

As we have shown above, Markides (2007) (p. 766) recommends that younger researchers "avoid the time-consuming exercise of trying to publish their research in managerial journals," implying that the time spent on practice-oriented papers would be wasted for one's scientific career. In this section we report on the extent to which researchers appear to follow Markides' advice and, in doing so, assume a conflict between the logics of basic and applied research.

To shed light on changing publication practices over the course of their careers, we identified 201 authors who are or have been affiliated with the top five American business schools ${ }^{9}$ (Wharton School, Harvard Business School, Columbia Business School, Stanford University, and MIT Sloan School of Management) in the period from 1961 to 2010 and who published at least one article in both the academic and practitioner-oriented genres of journals. We included the 110 authors whose academic career lasted for at least 20 years. To calculate the duration of careers, we searched the ISI Web of Knowledge/Social Science Citation Index for all publications of an author, drawing only on results under the subject areas categorized as "business" and "management" in order to exclude coincidentally homonymous authors. We considered the year in which the first publication of an author was published as the start of this person's academic career and treated the last year in which an author published new work as the end of that career. ${ }^{10}$ Our analysis requires the identification of a time span in which articles have been published, and we deemed the first ten years after the initial academic or practitioner-oriented publication as the early phase of a scholar's career, and the ten years before the last (included) publication as the late career phase, respectively.

With regard to the publications of all 110 authors, 813 academic and 268 practitioner-oriented publications fall into the first ten years of their academic careers. The same authors wrote 734 academic and 288 professional articles in the last ten years of their careers. In our sample, we identified Academy of Management Executive, Business Horizons, California Management Review, Fortune, Harvard Business Review, MIT Sloan Management Review (including prior names of this journal), Journal of Advertising Research, Organizational Dynamics, Quality Progress, Research-Technology Management, Training \& Development, and Workforce as practitioner-oriented journals.

Affiliation with a specific business school seems to strongly impact publication practices with regard to practitioneroriented and academic publications, going from an almost equal distribution in the early career phase at Harvard to only 9.20 percent of practitioner-oriented articles in the early career phase at Columbia (see Table 1). Nevertheless, at four of the five business schools, the percentage of publications in practitioner-oriented journals is higher in the late stage of the scholars' careers. Only MIT Sloan School of Management deviates from the proposed relation between career stages and the tendency to publish in practitioner-oriented journals; here scholars have a higher percentage of professional articles in their early career phase than in their late stage. The average number of academic publications per person indicates that adherence to the logic of basic research by publishing articles in academic journals is especially important in the early career phase, which is probably due to the pressure of achieving tenure. The results of chi-square tests indicate that the probability of publishing in a practitioneroriented journal is not independent of a given phase of an academic's career. This result is significant for Wharton and Stanford $(p<0.05)$. One might assume that the deviant result for MIT Sloan School of Management is due to other

\footnotetext{
${ }^{9}$ According to the Financial Times Global MBA Rankings 2011.

${ }^{10}$ As our data collection took place in 2011, the last possible year was 2010 , although the career of the selected authors might still be continuing.
} 
Table 1 Differences in publication practices in stages of a scholar's academic career: chi-square test of independence according to business school affiliation.

\begin{tabular}{|c|c|c|c|c|c|c|c|}
\hline & $\begin{array}{c}\text { Wharton } \\
\text { (\%) }\end{array}$ & $\begin{array}{c}\text { Harvard } \\
\text { (\%) }\end{array}$ & $\begin{array}{c}\text { Columbia } \\
(\%)\end{array}$ & $\begin{array}{c}\text { Stanford } \\
(\%)\end{array}$ & $\begin{array}{l}\text { MIT } \\
(\%)\end{array}$ & $\begin{array}{c}\text { Total } \\
(\%)\end{array}$ & $\begin{array}{c}\text { Total } \\
\text { without } \\
\text { MIT (\%) }\end{array}$ \\
\hline $\begin{array}{l}\text { Percentage of professional articles: } \\
\text { early career phase }\end{array}$ & 18.62 & 49.52 & 9.20 & 19.79 & 26.60 & 24.79 & 24.41 \\
\hline $\begin{array}{l}\text { Percentage of professional articles: } \\
\text { late career phase }\end{array}$ & 25.71 & 56.08 & 11.92 & 34.62 & 16.00 & 28.11 & 31.02 \\
\hline $\begin{array}{l}\text { Average of academic/professional } \\
\text { articles per person: early career phase }\end{array}$ & $8.2 / 1.9$ & $4.2 / 4.2$ & $12.3 / 1.3$ & $7.9 / 1.9$ & $6.6 / 2.4$ & $7.4 / 2.4$ & $7.6 / 2.4$ \\
\hline $\begin{array}{l}\text { Average of academic/professional } \\
\text { articles per person: late career phase }\end{array}$ & $7.2 / 2.5$ & $3.3 / 4.2$ & $12.3 / 1.5$ & $6.0 / 2.6$ & $8.0 / 1.5$ & $6.7 / 2.6$ & $6.4 / 2.9$ \\
\hline Chi-square & 4.76 & 1.72 & 0.62 & 4.96 & 6.39 & 2.98 & 9.36 \\
\hline$p$-value $<$ & 0.05 & n.s. & n.s. & 0.05 & $0.05^{*}$ & n.s. (0.1) & 0.005 \\
\hline
\end{tabular}

Table 2 Differences in publication strategies due to the stage of a scholar's academic career: chi-square test of independence according to generation cohorts.

\begin{tabular}{lcccc}
\hline & $1950 \mathrm{~s}(\%)$ & $1960 \mathrm{~s}(\%)$ & $1970 \mathrm{~s}(\%)$ & $1980 \mathrm{~s}(\%)$ \\
\hline Percentage of professional articles: early career phase & 36.11 & 32.84 & 20.56 & 23.76 \\
$\begin{array}{l}\text { Percentage of professional articles: late career phase } \\
\text { Average of academic/professional articles per person: }\end{array}$ & 42.86 & 30.15 & 21.15 & 32.10 \\
$\quad \begin{array}{l}\text { early career phase } \\
\text { Average of academic/professional articles per person: }\end{array}$ & $3.8 / 2.2$ & $5.9 / 2.9$ & $8.2 / 2.1$ & $8.0 / 2.5$ \\
$\quad$ late career phase & $4.0 / 3.0$ & $4.1 / 1.8$ & $8.6 / 2.3$ \\
$\begin{array}{l}\text { Chi-square } \\
\text {-value }<\end{array}$ & 0.37 & 0.27 & 0.04 & $6.8 / 3.2$ \\
\hline
\end{tabular}

factors like the increase of issues per year ${ }^{11}$ of the related MIT Sloan Management Review or changed recruiting policies. Thus, excluding MIT, the result of the chi-square test of independence is highly significant $(p<0.005)$.

This result led us to ask whether the tendency for authors to publish in practitioner-oriented journals in later phases of their career has gained momentum over the period of our study. A tendency in this direction can be seen as an indicator that academic publications in line with the logic of basic research have become more important in the field than practitioner-oriented publications that are shaped by the logic of applied research. Our findings indeed suggest that institutional changes in the field from 1961 onwards have also shaped publication practices. The publication of articles in top scholarly journals increasingly became a criterion of academic merit as well as one for promotional decisions (Macdonald \& Kam, 2007). To understand changing publication practices as a response to competing institutional logics, we created generation cohorts according to the decade of the first publication of an author registered on the ISI Web of Knowledge/Social Science Citation Index. Of the 110 authors in our sample, six authors belong to the 1950s, 23 to the 1960 s, 35 to the 1970 s, and 46 to the 1980 s generation cohort.

\footnotetext{
11 A third issue (Winter) was introduced in 1968, a fourth issue (Summer) in 1979.
}

The results (see Table 2) indicate that the tendency of scholars to shift practitioner-oriented publications to later years of their careers has become stronger in recent decades. While publishing academic articles has generally gained importance in both early and late career stages, the gap between the number of academic articles and the number of practitioner-oriented ones has widened. Concerning the influence of individual career stages, the first three generation cohorts reveal relatively constant percentages of practitioner-oriented publications in early and late career phases; while in the 1980s generation cohort, late career publication practices deviate strongly from those in early career phases (see Fig. 3). Remarkably, the results of the chi-square tests for the 1980s generation cohort show with high significance $(p<0.005)$ that the tendency to publish in practitioneroriented journals is not independent of the career phase of scholars. For the preceding generation cohorts, chi-square tests yield no significant results.

\section{Discussion and conclusion}

Our empirical study aimed at exploring how management scholars in their publication practices react to a situation of institutional complexity, namely the existence of two competing institutional logics, the logic of basic and the logic of applied research. Having outlined theoretical accounts on different strategies that actors can draw on to deal with 


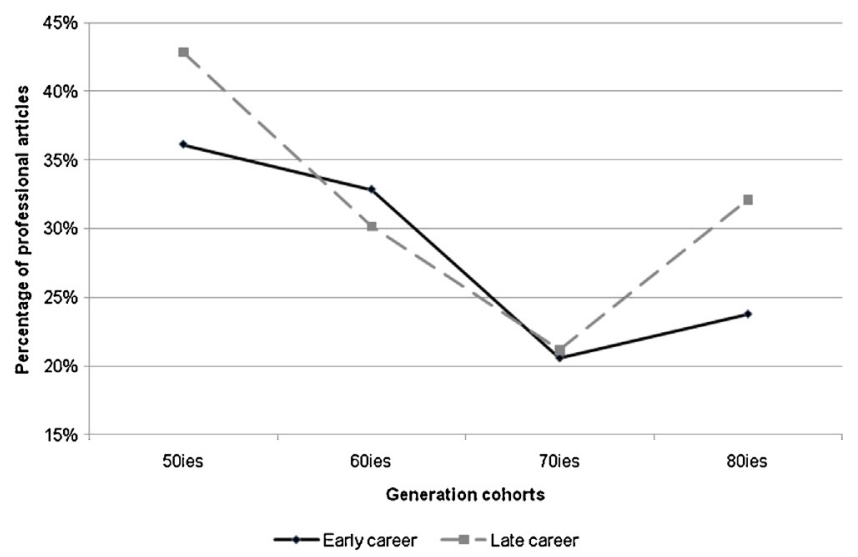

Fig. 3 Percentage of professional articles for different generation cohorts and career phases.

institutional complexity in section three, we now discuss our empirical results against this background.

Compartmentalization appears to be the dominant coping strategy of management scholars in response to competing institutional demands. Our results suggest, first, that this special form of decoupling occurs when scholars publish in separate outlets for different target audiences (academia versus management) and, second, it involves compartmentalization in the sense of time sequencing, especially with respect to the lifelong publications of management scholars. Scholars from leading business schools who happen to write in both academic and practitioner-oriented journals only selectively and cursorily base their articles for practitioners on their research. They enrich their discussions of practical problems with ideas inspired by their academic background knowledge, yet they do not mention any theories that framed their analyses or scientific methods to legitimize their practitioner-oriented recommendations. These findings indicate that scholars separate the two spheres of academic research and of management practice in their journal publication practices. It is likely that they associate each sphere with a particular institutional logic (the sphere of academic research with the logic of basic research and the sphere of management practice with the logic of applied research) and with particular roles (that of a scholar, on the one hand, and a consultant, on the other) (Werr \& Greiner, 2008).

Authors who publish in academic as well as in practitioneroriented journals do the latter predominantly in later years of their career. In their early career phases, scholars tend to demonstrate their mastery of rigorous research, since this is what advances their careers. At the same time, they, or rather some of them, also do not resist demands stemming from the logic of applied research but conform to them in another (i.e., later) period (when, presumably, an adoption of applied research practices no longer affects their tenure). Thus by sequentially separating academic-oriented from practitioner-oriented publications, management scholars are able to comply with each logic in a particular period of their careers. This coping response to plural institutional demands is an interesting example of sequential compartmentalization that - unlike short-term tactics - relates to individuals' strategic career perspectives.
Compartmentalization as a strategy further corresponds to a finding from our qualitative content analysis of the 127 articles that explicitly deal with the perception of the rigor-relevance gap. In their discussion of institutional demands, authors evoke different notions of compartmentalization. Most of them suggest that both logics can be pursued separately by, for instance, putting in more effort to "translate" research results to practitioners afterwards by either publishing in professional journals or by intensifying the discussion of "practical implications" in the respective journal article sections. Thus, while most authors assume that different efforts and even different epistemologies are necessary, they are convinced that it is possible to pursue rigorous and relevant research at the same time. Gulati (2007), for instance, describes compartmentalization as being linked to distinct scholar identities: the "management types" and the "serious scholars." Few articles (Simon, 1967) question whether both logics can be satisfied and seem to suggest a strategy of resisting one institutional demand, in this case by defying the importance of the logic of applied research. Also very rare are the calls from the opposing side advocating more practical relevance through the adoption of the logic of applied research - to introduce dramatic changes to the academic reward and promotion system (Pfeffer, 2007). Compartmentalization as the separation of conflicting forces thus proves to be the dominant means to prevent clashes.

Balancing conflicting demands, another coping strategy identified by Kraatz and Block (2008), is also relevant, though less obvious, when accounting for management scholars' responses. Although scholars do not only comply with some claims while denying the importance of others, they generally place special emphasis on rigor while implying that this criterion is, simultaneously, the necessary - if not sufficient - condition for relevance. They constantly try to create the impression, for example in Presidential Addresses at Academy of Management Meetings, that rigor and relevance are not really in conflict, that research excellence is the basis of relevance, that the better the research quality, the higher the relevance of concepts offered to practitioners. The management research field thus seems to expect researchers to establish a balance between activities in fulfilment of conflicting institutional demands.

We interpret the rising number of articles on rigor and relevance as a sign that management scholars increasingly acknowledge the importance of paying tribute to the demand for more practical relevance and also as a sign that reflects the awareness of a tension between different institutional logics. The reaction of management scholars can be seen as a balancing or, in the terms of Pache and Santos (2010), as a compromise strategy: they produce talk about the practical needs of management, thereby acknowledging an obligation and fulfilling the minimum requirements for accepting the claims for practical relevance. By giving the importance of applied research a voice in academic publications, the authors demonstrate their awareness of the need for practical relevance. This evidence of their awareness can be used in dialogues with the press, politicians, and representatives of practitioner associations. However, the majority of practitioners will not take notice of this debate. Studies have shown that practitioners pose different questions than academics do and rarely read articles in academic journals 
(Gopinath \& Hoffman, 1995; McKenzie, Wright, Ball, \& Baron, 2002). The difficulty to reach practitioner audiences with academic journals becomes even more obvious when we consider "practical implication" sections in academic articles. While our data indicates that practical implications are increasingly mentioned, this information does not reach the managers and thus remains decoupled from management practice. Furthermore, while the numbers of articles with sections on how managers might apply research results increases, scholars are not required to present actual changes in practice or prove that the effects of such changes have moved in the direction of the practical implications that they identified.

So what we see is that the logic of applied research actually triggers changes in management scholars' publications. However, these changes can hardly be related to the desired outcome of an increased practical relevance of research. Few scholars apply the methodological practices that are associated with the logic of applied research, including Mode 2, action research, evidence-based management, and design approach. This finding suggests that management scholars allow changes to take place at the discursive level of their research while central practices of their research - the methods they use - remain shaped by the logic of basic research. Considering that changes take place largely on a symbolic level, the response of management scholars can be classified as a "classical" form of decoupling, that is, policypractice decoupling (Bromley \& Powell, 2012; Meyer \& Rowan, 1977) or decoupling of talk and action in Brunsson's terms Brunsson (1993, 2002). If consistency between talk and action cannot be achieved, the actors, in our case management scholars, can resort to justification, that is, to explanations of how ideas are in principle in accordance with planned or accomplished actions. Brunsson (2002) (p. 172) described this form of decoupling as hypocrisy, since it means "that ideas and action do not directly support one another. ... We could say that the action is being protected, in that management [in our case the community of management scholars] satisfies by talk the demands which the action does not meet."

Talking about the need to use "applied" methods seems to indicate that scholars are acting according to the exigencies of the logic of applied research, whereby they would generate confidence and good faith among those field members who expect changes in this regard (Meyer \& Rowan, 1977). Yet since this discourse on new methodologies does not lead to changes in the chosen research methods on a broader scale, it can be seen as an example of an avoidance tactic that aims to conceal nonconformity and buffer internal activities from external audiences (Pache \& Santos, 2010).

To summarize, we find that management scholars handle the institutional complexity of two competing logics in their field mainly by using balancing and compartmentalization strategies (Kraatz \& Block, 2008), or compromise and avoidance strategies (Pache \& Santos, 2010). It seems when avoidance tactics like policy-practice decoupling are employed, the logic of basic research remains unaffected and continues to provide the dominant organizing principles for management scholars' publication practices. However, the logic of applied research has already brought about certain changes in publications, and its existence appears to depend on compromises with the dominant logic of basic research. These individual responses to institutional complexity can explain how two presumably competing institutional logics coexist in the field.

Reflecting on the results, we find that the conflict between rigor and relevance does not seem to cause serious trouble for management researchers. It is a conflict that the members of the scholarly community predominantly fight out among themselves. Practitioners who are usually portrayed as the victims of management studies' focus on basic research usually do not assume an active role in this conflict. Since very few of them read academic management journals (Gopinath \& Hoffman, 1995; McKenzie et al., 2002), practitioners in general are not capable of estimating the damage incurred by them as a result of management scholars' assumed (over-)emphasis of basic research. Probably it does not even occur to them that their interests might not appropriately be taken care of by management researchers. Many of them read articles that they find inspiring written by management scholars in practitioner-oriented journals such as Harvard Business Review, California Management Review or MIT Sloan Management Review, and they listen to keynotes by management scholars at meetings of professional organizations. Perhaps the company they are working for once hired a scholar consultant - a professor from a top university who simultaneously runs a consultancy (Adler \& Beer, 2008, p. 552; Werr \& Greiner, 2008, p. 94) - for managing a change project to management's full satisfaction. Overall, they might find the knowledge of newly hired graduates sufficiently useful with regard to their company practice. In addition, the business school rankings of the Financial Times or Business Week create the impression that graduates are furnished with useful knowledge. Those who criticize a lack of relevance in management research are predominantly the management scholars themselves. Those who criticize management research for being too strongly dedicated to basic research, in a self-referential fashion, construct problems inflicted on practitioners, problems that emerge from an overemphasis of basic research. As Thorpe, Eden, Bessant, and Ellwood (2011) (p. 420) remark: “There is an irony here that the Academy's default reaction to an accusation of a lack of relevance is to engage in yet another academic debate." The irony is even greater when one considers that members of the community launched the accusation. Some contributors to this debate may not have altruistic motives. For them, the debate offers a chance to publish in a new field and earn impact factor points. Thorpe et al. (2011) (p. 429) hold that "the rigour-relevance debate in management research endures, with little prospect of resolution."

Since practitioners do not read academic management journals, ironically, they are also unable to value the innumerable inspirations they could possibly draw from reading the "implications for practice sections" that top-ranked journals require from their authors (see, e.g., "AMJ Information for Contributors, 2014"). Authors obediently speculate about practical implications their basic research could possibly entail. They must be aware that neither the editor nor the reviewers are practitioners themselves. They are thus unable to adequately evaluate practical implications from a practitioner's perspective. Furthermore, the overwhelming majority of readers of these implications would not belong to the target audience. 
It is not at all surprising that management researchers adhere to the logic of basic research because their employers, the business schools, have to uphold the principle of rigorous scientific research and to make sure that scholars respond to this demand in order to retain their school's position among research universities. Achievement in basic research is the dominant criterion for an academic career, for acquiring posts at prestigious schools, for being invited as editors and coeditors of prestigious journals, for receiving awards of excellence - management scholars share all these distinctions with scholars from other disciplines and perceive them as the major sources of their identities. It is also not surprising that management scholars experience a need to produce research that is useful for the practice of management. What is surprising is that the majority of management researchers are convinced that research that is useful for practice should follow the same logic as research that is regarded as contributing to the advancement of theory. Research is about explaining phenomena. Only people trained in discussing theories and applying scientific methods are able to generate research questions that advance academic theories and methods. Practitioners are confronted with problems of a different kind. In their attempts to find answers to the questions they are confronted with, practitioners find themselves confronted with a plethora of publications in scholarly journals that they, not being trained in theory discussions or scientific methodologies, have great difficulty to understand let alone to relate them to their problems. These texts can only be understood in the context of the scientific debate to which these publications intend to contribute.

In this article we have argued that the different institutional logics of applied and basic research are the reason for different publication practices of management researchers as they try to handle this situation of institutional complexity. We are thus able to explain changing publication practices like an increase in "practical implications" sections in journal articles, the heightened attention given to the discussion of the rigor-relevance gap, and the publication in practitioneroriented journals during the later stages of one's career, as a reaction to competing institutional demands in the field of management research. However, it might be helpful to tone down the rigor-relevance debate and to accept the publishing game in management studies as a situation of institutional complexity that cannot be resolved easily.

\section{Appendix A. Supplementary data}

Supplementary material related to this article can be found, in the online version, at http://dx.doi.org/10. 1016/j.scaman.2015.02.001.

\section{References}

Adler, N., \& Beer, M. (2008). Collaborative R\&D in management: The practical experience of FENIX and TruePoint in bridging the divide between scientific and managerial goals. In A. B. R. Shani, S. A. Mohrman, W. A. Pasmore, B. Stymne, \& N. Adler (Eds.), Handbook of Collaborative Management Research (pp. 545-565). Los Angeles: Sage.

Amabile, T. M., Patterson, C., Mueller, J., Odomirok, P. W., Marsh, M., \& Kramer, S. J. (2001). Academic-practitioner collaboration in management research: A case of cross-profession collaboration. Academy of Management Journal, 44, 418-431.

Astley, G. (1984). Subjectivity, sophistry and symbolism in management science. Journal of Management Studies, 21, 259-272.

Astley, G. \& \& Zammuto, R. F. (1992). Organization science, managers, and language games. Organization Science, 3, 443-460.

Barney, J. B. (2005). Should strategic management research engage public policy debates? Academy of Management Journal, 48, 945-948.

Bartunek, J. M. (2007). Academic-practitioner collaboration need not require joint or relevant research: Toward a relational scholarship of integration. Academy of Management Journal, 50, $1323-1332$.

Beer, M. (2001). Why management research findings are unimplementable: An action science perspective. Reflections, 2, 58-65.

Bell, M. P. (2009). Introduction: Special section, doing work that matters. Academy of Management Learning \& Education, 8, 9698.

Bennis, W. G., \& O'Toole, (2005). J. How business schools lost their way. Harvard Business Review, 83, 96-104.

Bettis, R. A. (1991). Strategic management and the straightjacket: An editorial essay. Organization Science, 2, 315-319.

Bourgeois, L. J., \& Eisenhardt, K. M. (1988). Strategic decision processes in high velocity environments: Four cases in the microcomputer industry. Management Science, 34, 816-835.

Bromley, P., \& Powell, W. W. (2012). From smoke and mirrors to walking the talk: Decoupling in the contemporary world. Academy of Management Annals, 6, 483-530.

Brunsson, N. (1993). Ideas and actions: Justification and hypocrisy as alternatives to control. Accounting, Organizations and Society, 18, 489-506.

Brunsson, N. (2002). The organization of hypocrisy: Talk, decisions and actions in organizations. Copenhagen: Copenhagen Business School Press.

Burgoyne, J., \& James, K. T. (2006). Towards best or better practice in corporate leadership development: Operational issues in Mode 2 and design science research. British Journal of Management, 17, 303-316.

Busenitz, L. W., West lii, G. P., Shepherd, D., Nelson, T., Chandler, G. N., \& Zacharakis, A. (2003). Entrepreneurship research in emergence: Past trends and future directions. Journal of Management, 29, 285-308.

Cohen, D. J. (2007). The very separate worlds of academic and practitioner publications in human resource management: Reasons for the divide and concrete solutions for bridging the gap. Academy of Management Journal, 50, 1013-1019.

de Rond, M., \& Miller, A. N. (2005). Publish or perish: Bane or boon of academic life? Journal of Management Inquiry, 14, 321-329.

Druskat, V. U., \& Wheeler, J. V. (2003). Managing from the boundary: The effective leadership of self-managing work teams. Academy of Management Journal, 46, 435-457.

Eden, C., \& Huxham, C. (1996). Action research for management research. British Journal of Management, 7, 75-86.

Eisenhardt, K. M. (1989). Making fast decisions in high-velocity environments. Academy of Management Journal, 32, 543-576.

Eisenhardt, K. M., \& Bourgeois, L. J. (1988). Politics of strategic decision making in high-velocity environments: Toward a midrange theory. Academy of Management Journal, 31, 737-770.

Eisenhardt, K. M., \& Brown, S. L. (1998). Time pacing: Competing in markets that won't stand still. Harvard Business Review, 76, 59-69.

Eisenhardt, K. M., \& Brown, S. L. (1999). Patching. Harvard Business Review, 77, 72-82.

Fourcade, M., \& Khurana, R. (2013). From social control to financial economics: The linked ecologies of economics and business in twentieth century America. Theory and Society, 42, 121-159.

Geletkanycz, M. A., \& Hambrick, D. C. (1997). The external ties of top executives: Implications for strategic choice and performance. Administrative Science Quarterly, 42, 654-681. 
Gopinath, C., \& Hoffman, R. C. (1995). The relevance of strategy research: Practitioner and academic viewpoints. Journal of Management Studies, 32, 575-594.

Gordon, R. A., \& Howell, J. E. (1959). Higher Education for Business. New York: Columbia University Press.

Greenwood, R., Raynard, M., Kodeih, F., Micelotta, E. R., \& Lounsbury, M. (2011). Institutional complexity and organizational responses. Academy of Management Annals, 5, 317-371.

Gulati, R. (2007). Tent poles, tribalism, and boundary spanning: The rigor-relevance debate in mangement research. Academy of Management Journal, 50, 775-782.

Hambrick, D. C., Davison, S. C., Snell, S. A., \& Snow, C. C. (1998). When groups consist of multiple nationalities: Toward a new understanding of the implications. Organization Studies, 19, 181-205.

Hambrick, D. C. \& Fredrickson, J. W. (2005). Are you sure you have a strategy? Academy of Management Executive, 19, 51-62.

Hambrick, D. C., \& Jackson, E. M. (2000). Outside directors with a stake: The linchpin in improving governance. California Management Review, 42, 108-127.

Hodgkinson, G. P., Herriot, P., \& Anderson, N. (2001). Re-aligning the stakeholders in management research: Lessons from industrial, work and organizational psychology. British Journal of Management, 12, S41-S48.

Hodgkinson, G. P., \& Rousseau, D. M. (2009). Bridging the rigourrelevance gap in management research: It's already happening! Journal of Management Studies, 46, 534-546.

Huff, A. S. (2000). 1999 Presidential address: Changes in organizational knowledge production. Academy of Management Review, $25,288-293$.

Information for contributors. Academy of management journal. (2014). Lhttp://aom.org/Publications/AMJ/Information-forContributors.aspx.) Accessed 14.10.14.

Ivancevich, J. M., Duening, T. N., \& Lidwell, W. (2005). Bridging the manager-organizational scientist collaboration gap. Organizational Dynamics, 34, 103-117.

Kelemen, M., \& Bansal, P. (2002). The conventions of management research and their relevance to management practice. British Journal of Management, 13, 97-108.

Khurana, R. (2007). From higher aims to hired hands: The social transformation of American business schools and the unfulfilled promise of management as a profession. Princeton: Princeton University Press.

Kieser, A., Nicolai, A., \& Seidl, D. (2015). The practical relevance of management research: Turning the debate on relevance into a rigorous scientific research program. Academy of Management Annals, 9, 143-233.

Kieser, A., \& Leiner, L. (2009). Why the rigour-relevance gap in management research is unbridgeable. Journal of Management Studies, 46, 516-533.

Kraatz, M. S., \& Block, E. S. (2008). Organizational implications of institutional pluralism. In R. Greenwood, C. Oliver, K. SahlinAndersson, \& R. Suddaby (Eds.), Handbook of Organizational Institutionalism (pp. 243-275). New York: Sage.

Lockett, A., Moon, J., \& Visser, W. (2006). Corporate social responsibility in management research: Focus, nature, salience and sources of influence. Journal of Management Studies, 43, 115-136.

Lounsbury, M. (2007). A tale of two cities: Competing logics and practice variation in the professionalization of mutual funds. Academy of Management Journal, 50, 289-307.

Ludmerer, K. M. (2010). Time to Heal: American Medical Education from the Turn of the Century to the Era of Managed Care. Oxford: Oxford University Press.

Macdonald, S., \& Kam, J. (2007). Ring a ring o' roses: Quality journals and gamesmanship in management studies. Journal of Management Studies, 44, 640-655.

MacLean, D., Maclntosh, R. , \& Grant, S. (2002). Mode 2 management research. British Journal of Management, 13, 189-201.
Markides, C. (2007). In search of ambidextrous professors. Academy of Management Journal, 50, 762-768.

Marquis, C., \& Lounsbury, M. (2007). Vive la résistance: Competing logics and the consolidation of U.S. community banking. Academy of Management Journal, 50, 799-820.

McGahan, A. (2007). Academic research that matters to managers: On zebras, dogs, lemmings, hammers, and turnips. Academy of Management Journal, 50, 748-753.

McGrath, R. G. (2007). No longer a stepchild: How the management field can come into its own. Academy of Management Journal, 50, 1365-1378.

McKenzie, C. J., Wright, S., Ball, D. F., \& Baron, P. J. (2002). The publications of marketing faculty-who are we really talking to? European Journal of Marketing, 36, 1196-1208.

Merton, R. K. (1973). The Sociology of Science: Theoretical and Empirical Investigations. Chicago: University of Chicago Press.

Meyer, J. W., \& Rowan, B. (1977). Institutionalized organizations: Formal structure as myth and ceremony. American Journal of Sociology, 83, 340-363.

Meyer, R. E., \& Höllerer, M. A. (2010). Meaning structures in a contested issue field: A topographic map of shareholder value in Austria. Academy of Management Journal, 53, 1241-1262.

Miller, D., Greenwood, R., \& Hinings, C. R. (1997). Creative chaos versus munificent momentum: The schism between normative and academic views of organizational change. Journal of Management Inquiry, 6, 71-78.

Mintzberg, H. (1977). Policy as a field of management theory. Academy of Management Journal, 2, 88-103.

Mitev, N., \& Venters, W. (2009). Reflexive evaluation of an academicindustry research collaboration: Can Mode 2 management research be achieved? Journal of Management Studies, 46, 733-754.

Mohrman, S. A., Gibson, C. B., \& Mohrman, A. M. J. (2001). Doing research that is useful to practice: A model and empirical exploration. Academy of Management Journal, 44, 357-375.

Mowday, R. T. (1997). Reaffirming our scholarly values. Academy of Management Review, 22, 335-345.

Nicolai, A. (2004). The bridge to the 'real world': Applied science fiction or a 'schizophrenic tour de force'? Journal of Management Studies, 41, 951-976.

Pache, A. -C., \& Santos, F. (2010). When worlds collide: The internal dynamics of organizational responses to conflicting institutional demands. Academy of Management Review, 35, 455-476.

Pfeffer, J. (2007). A modest proposal: How we might change the process and product of managerial research. Academy of Management Journal, 50, 1334-1345.

Pfeffer, J., \& Fong, C. (2002). The end of business schools? Less success than meets the eye. Academy of Management Learning \& Education, 1, 78-95.

Pierson, F. C. (1959). The education of American businessmen: A study of university-college programs in business administration. New York: McGraw-Hill.

Podsakoff, P. M., MacKenzie, S. B., Podsakoff, N. P., \& Bachrach, D. G. (2008). Scholarly influence in the field of management: A bibliometric analysis of the determinants of university and author impact in the management literature in the past quarter century. Journal of Management, 34, 641-720.

Reay, T., \& Hinings, C. R. B. (2005). The recomposition of an organizational field: Health care in Alberta. Organization Studies, 26, 351-384.

Reay, T. \& \& Hinings, C. R. B. (2009). Managing the rivalry of competing institutional logics. Organization Studies, 30, 629-652.

Rosenberg, C. E. (1987). The Care of Strangers: The Rise of America's Hospital System. New York: Basic Books.

Rothstein, W. G. (1987). American Medical Schools and the Practice of Medicine: A History. New York: Oxford University Press.

Rousseau, D. M., \& McCarthy, S. (2007). Educating managers from an evidence-based perspective. Academy of Management Learning \& Education, 6, 84-101. 
Rynes, S. L., Bartunek, J. M., \& Daft, R. D. (2001). Across the great divide: Knowledge creation and transfer between practitioners and academics. Academy of Management Journal, 44, 340-355.

Saari, L. (2007). Bridging the worlds. Academy of Management Journal, 50, 1043-1045.

Salipante, P., \& Aram, J. D. (2003). Managers as knowledge generators: The nature of practitioner-scholar research in the nonprofit sector. Nonprofit Management \& Leadership, 14, 129-150.

Schibrowsky, J. A., Peltier, J. W., \& Boyt, T. E. (2002). A professional school approach to marketing education. Journal of Marketing Education, 24, 43-56.

Schlossman, S., Sedlak, M., \& Wechsler, H. (1987). The 'new look': The Ford Foundation and the revolution in business education. Selections, 14, 8-28.

Scott, W. R., Ruef, M., Mendel, P. J., \& Caronna, C. A. (2000). Institutional Change and Healthcare Organizations. Chicago: University of Chicago Press.

Shapiro, D. L., Kirkman, B. L., \& Courtney, H. G. (2007). Perceived causes and solutions to the translation problem in management research. Academy of Management Journal, 50, 249-266.

Simon, H. A. (1967). The business school: A problem in organizational design. Journal of Management Studies, 4, 1-16.

Starkey, K., Hatchuel, A., \& Tempest, S. (2009). Management research and the new logics of discovery and engagement. Journal of Management Studies, 46.

Starkey, K., \& Madan, P. (2001). Bridging the relevance gap: Aligning stakeholders in the future of management research. British Journal of Management, 12, S3-S26.

Tempest, S., \& Starkey, K. (2004). The effects of liminality on individual and organizational learning. Organization Studies, 25, 507-527.

Thomas, K. W., \& Tymon, W. G. J. (1982). Necessary properties of relevant research: Lessons from recent criticisms of the organizational sciences. Academy of Management Review, 7, 345-352.

Thornton, P. (2001). Personal versus market logics of control: A historically contingent theory of the risk of acquisition. Organization Science, 12, 294-311.
Thornton, P. (2002). The rise of the corporation in a craft industry: Conflict and conformity in institutional logics. Academy of Management Journal, 45, 81-101.

Thornton, P., \& Ocasio, W. (2008). Institutional logics. In R. Greenwood, C. Oliver, K. Sahlin, \& R. Suddaby (Eds.), The Sage Handbook of Organizational Institutionalism (pp. 99-129). Los Angeles: Sage.

Thornton, P., Ocasio, W., \& Lounsbury, M. (2012). The Institutional Logics Perspective: A New Approach to Culture, Structure, and Process. Oxford: Oxford University Press.

Thorpe, R., Eden, C., Bessant, J., \& Ellwood, P. (2011). Rigour, relevance and reward: Introducing the knowledge translation value-chain. British Journal of Management, 22, 420-431.

Tranfield, D., \& Starkey, K. (1998). The nature, social organization and promotion of management research: Towards policy. British Journal of Management, 9, 341-353.

Trank, C., \& Rynes, S. L. (2003). Who moved our cheese? Reclaiming professionalism in business education. Academy of Management Learning \& Education, 2, 189-205.

Tushman, M. L., \& O'Reilly III, C. (2007). Research and relevance: Implications of Pasteur's quadrant for doctoral programs and faculty development. Academy of Management Journal, 50, 769-774.

Van Aken, J. E. (2004). Management research based on the paradigm of the design sciences: The quest for field-tested and grounded technological rules. Journal of Management Studies, 41, 219-246.

Van Aken, J. E. (2005). Management research as a design science: Articulating the research products of Mode 2 knowledge production in management. British Journal of Management, 16, 19-36.

Van de Ven, A. H., \& Johnson, P. E. (2006). Knowledge for theory and practice. Academy of Management Review, 31, 902-921.

Vermeulen, F. (2007). "I shall not remain insignificant": Adding a second loop to matter more. Academy of Management Journal, 50, 754-761.

Werr, A., \& Greiner, L. (2008). Collaboration and the production of management knowledge in research, consulting, and management practice. In A. B. R. Shani, S. A. Mohrman, W. A. Pasmore, B. Stymne, \& N. Adler (Eds.), Handbook of Collaborative Management Research (pp. 93-117). Los Angeles: Sage. 